Article

\title{
Fostering Lavender as a Source for Valuable Bioactives for Food and Pharmaceutical Applications through Extraction and Microencapsulation
}

\author{
Simona Daniela Radu (Lupoae) ${ }^{1}$, Liliana Mihalcea ${ }^{1}$, Iuliana Aprodu ${ }^{1}$ D, Sonia A. Socaci ${ }^{2}$ (D), \\ Mihaela Cotârleț $^{1}$, Elena Enachi ${ }^{1}{ }^{(D)}$, Oana Crăciunescu ${ }^{3}\left(\mathbb{D}\right.$, Vasilica Barbu ${ }^{1} \mathbb{D}$, Anca Oancea ${ }^{3}$, \\ Francisc Vasile Dulf ${ }^{4}{ }^{(D)}$, Petru Alexe ${ }^{1}$, Gabriela Elena Bahrim ${ }^{1}$ (D), Gabriela Râpeanu ${ }^{1}$ \\ and Nicoleta Stănciuc $1, *$ (D)
}

1 Faculty of Food Science and Engineering, Dunărea de Jos University of Galati, Domnească Street 111, 800201 Galati, Romania; radu.daniela1308@yahoo.com (S.D.R.); Liliana.Mihalcea@ugal.ro (L.M.); Iuliana.Aprodu@ugal.ro (I.A.); Mihaela.Cotarlet@ugal.ro (M.C.); Elena.Ionita@ugal.ro (E.E.); Vasilica.Barbu@ugal.ro (V.B.); Petru.Alexe@ugal.ro (P.A.); Gabriela.Bahrim@ugal.ro (G.E.B.); Gabriela.Rapeanu@ugal.ro (G.R.)

2 Faculty of Food Science and Technology, Department of Food Science, University of Agricultural Sciences and Veterinary Medicine Cluj-Napoca, Calea Manastur 3-5, 400372 Cluj-Napoca, Romania; sonia.socaci@usamvcluj.ro

3 National Institute of Research and \& Development for Biological Sciences, 296 Splaiul Independentei, 060031 București, Romania; oana_craciunescu2009@yahoo.com (O.C.); oancea.anca@gmail.com (A.O.)

4 Faculty of Agriculture, Department of Environmental and Plant Protection, University of Agricultural Sciences and Veterinary Medicine Cluj-Napoca, Calea Manastur 3-5, 400372 Cluj-Napoca, Romania; francisc_dulf@yahoo.com

* Correspondence: Nicoleta.Stanciuc@ugal.ro; Tel.: +40-0336-130-183

Academic Editors: Lillian Barros, Antonios Chrysargyris, Andrei Mocan and Nikos Tzortzakis

Received: 14 October 2020; Accepted: 26 October 2020; Published: 28 October 2020

\begin{abstract}
Lavender flowers were used in this study as a source of phytochemicals as naturally occurring antioxidants. Two different extraction techniques were applied, such as ultrasound-assisted (UAE) and supercritical fluids (SCE) methods. The comparative evaluation of the phytochemicals profile evidenced a higher content of chlorophyll $a$ and $b$ of $5.22 \pm 0.12 \mathrm{mg} / \mathrm{g}$ dry weight (D.W.) and $2.95 \pm 0.16 \mathrm{mg} / \mathrm{g}$ D.W, whereas the carotenoids content was $18.24 \pm 0.04 \mathrm{mg} / \mathrm{g}$ D.W. in the SCE extract. Seven main compounds were found in both extracts: $\beta$-linalool, eucalyptol, linalool acetate, $\beta$-trans-ocimene, and limonene in SCE and linalool acetate, $\beta$-linalool, 6-methyl-2-(2-oxiranyl)-5-hepten-2-ol, linalool oxide, lavandulyl acetate and camphor in UAE. The (n-3) acids had a higher contribution in SCE. The extracts were microencapsulated in different combinations of wall materials based on polysaccharides and milk proteins. The four variants showed different phytochemical and morphological profiles, with a better encapsulating efficiency for proteins (up to 98\%), but with a higher content of encapsulated carotenoids for polysaccharides, the latter showing remarkable antimicrobial activity against selected microorganisms. Carboxymethyl cellulose and whey proteins led to a double encapsulation of lipophilic compounds. The powders were tested in two food matrices as ingredients, with multiple targeted functions, such as flavoring, antimicrobial, antioxidant activity that can successfully replace synthetic additives.
\end{abstract}

Keywords: lavender; extraction; supercritical fluids extraction; phytochemicals; microencapsulation; added-value; food flavoring 


\section{Introduction}

Our daily diets involve large quantities of many pigments, especially carotenoids, anthocyanins, and chlorophylls [1]. These compounds possess important biological functions in humans against major disorders like cancer, cardiovascular diseases, cataract, arteriosclerosis, macular degeneration, and other age-related diseases [2]. The health benefits of chlorophylls include anti-oxidant, anti-inflammatory, anti-bacterial, anti-carcinogenic, deodorizing, and wound healing activities [3]. Carotenoids offer beneficial effects in preventing some types of cancer, cardiovascular and degenerative diseases. Polyphenols, a class of low molecular weight secondary plant metabolites which includes flavonoids, exhibit excellent antioxidant properties. These compounds are well known for their antioxidant, antimicrobial, anti-carcinogenic activities, neuroprotective effects [4], and anti-inflammatory activities [5]. Therefore, the use of plant extracts as functional ingredients in various food, beverage and cosmetic applications is gaining growing interest. However, despite all these health benefits, there are limitations to the commercial-scale application of bioactives as natural colorants because they are very susceptible to environmental stresses exerted by oxygen, enzymes, light, high temperature, and acidic or alkaline $\mathrm{pH}$, which result in degradation, oxidation, isomerization, and discoloration [6].

In recent years, the microencapsulation techniques aiming to develop a proper environment for different susceptible bioactives in a stable wall matrix as a mean of protecting functional compounds from processing conditions (like oxygen, $\mathrm{pH}$, ionic strength, and temperature) and improving the bioavailability have gained significant interest. Microencapsulation allows creation of a physical barrier between the core and the wall materials, thus protecting the material from ambient conditions such as light, temperature, oxygen, humidity, and from interaction with other substances [7]. The key factors for an efficient microencapsulation are the type of wall material and the characteristics of compounds to be encapsulated, the microencapsulation techniques and process parameters [8].

Lavenders are aromatic evergreen shrubs from Lamiaceae family that have been traditionally used as culinary herbs and medicine for headaches, digestive troubles, burns, skin sores and insect bites [9]. Lavandula ssp. are well known and studied for the content in essential oils. For example, the essential oils from L. stoechas ssp. luisieri were analyzed and their antifungal, anti-inflammatory and antioxidant activities evidenced [10]. The essential oils from L. pedunculata were also analyzed and their antifungal activity demonstrated by Zuzarte et al. [11]. Teixeira et al. [12] suggested also that several extracts of both species showed antibacterial activity, anticholinesterase inhibition and antioxidant capacity.

The commercial interest for lavenders is due to the potential application in the fragrance industry (soaps, colognes, perfumes, skin lotion and other cosmetics), in aromatherapy (relaxant), in pharmaceutical preparations for its therapeutic effects as a sedative, spasmolytic, antiviral and antibacterial agent [13]. However, lavender has been employed in food manufacturing as natural flavoring for beverages, ice cream, candy, baked goods and chewing gum [14].

This study aimed to provide a scientific basis for using lavender as a source of bioactives in the food industry, with targeted functions, such as flavoring, antioxidants and antimicrobials, knowing that lavender is less exploited for its content in carotenoid or polyphenolic compounds. A preliminary step was employed, selecting two extraction techniques, such as a combined ultrasound assisted method, involving the use of the organic solvents, and supercritical $\mathrm{CO}_{2}$ fluids extraction, followed by the comparison of the profiles, thus targeting different bioactives, such as carotenoids, polyphenols, fatty acids and volatiles, from the perspectives of using extracts as oleoresins and/or nutraceuticals. Secondly, considering the well-known low stability of the bioactive compounds, the obtained extracts were microencapsulated in different combinations, using agar as basic encapsulant material and various adjuvants, such as carboxymethyl cellulose, acacia gum, whey protein and casein. Therefore, four experimental variants were obtained and characterized in terms of microencapsulation efficiency, phytochemical content (chlorophylls, carotenoids, polyphenols and flavonoids), antioxidant, cytotoxicity, and antimicrobial activities. The powders' structure and morphology were analyzed 
by confocal laser microscopy. Further, the powders' functionality was tested in two food products, namely ice cream and macaroons.

\section{Materials and Methods}

\subsection{Reagents}

Folin-Ciocalteu's phenol reagent, sodium carbonate $\left(\mathrm{Na}_{2} \mathrm{CO}_{3}\right)$, sodium nitrite $\left(\mathrm{NaNO}_{2}\right)$, aluminum chloride $\left(\mathrm{AlCl}_{3}\right)$, sodium hydroxide $(\mathrm{NaOH})$, methanol, gallic acid, catechin, 1,1-diphenyl-2 picrylhydrazyl (DPPH), 6-Hydroxy-2,5,7,8-tetramethylchromane-2-carboxylic acid (Trolox), and the lipid standards and chemicals (used for oil extraction, fractionation, and preparation of fatty acid methyl esters (FAMEs)) were purchased from Sigma-Aldrich (Steinheim, Germany). Carbon dioxide with 99.99\% purity was supplied by Messer S.A., Romania. For cell culture experiments, Minimum Essential Medium (MEM), fetal bovine serum (FBS), an L-glutamine, mixture of antibiotics (penicillin, streptomycin, neomycin: PSN) and Neutral red (NR) were purchased from Merck (Darmstadt, Germany). The NCTC (L cell, L-929, derivative of Strain L] (ATCC $\left(C C L-1^{\mathrm{TM}}\right.$ ) clone L929 cell line of mouse fibroblasts was from European Collection of Authenticated Cell Cultures (Sigma-Aldrich, Steinheim, Germany).

\subsection{Extraction of Phytochemicals from Lavender}

The aerial parts of lavender flower (Lavandula angustifolia) were collected from natural populations occurring throughout the south-eastern regions of Romania (Galați, Romania), in July 2018. The plant material was air-dried at $40^{\circ} \mathrm{C}$ and powdered. Two types of extractions were performed: one using organic solvents such as $n$-hexane and acetone (in ratio of 3:1, v $\cdot v^{-1}$ ) and ultrasonication (onwards called ultrasound assisted extract-UAE) and extraction using supercritical $\mathrm{CO}_{2}$ (onwards called SCE) to obtain extracts rich in essential oils and phytochemicals, such as volatiles, phenolics, chlorophylls and carotenoids.

\subsection{Extraction of Phytochemicals from Lavender Using Ultrasound-Assisted Method}

The phytochemicals were extracted from the grounded lavender by adding $10 \mathrm{~mL}$ of $n$-hexan:acetone $\left(3: 1, v \cdot v^{-1}\right)$ to $2 \mathrm{~g}$ of powder [15]. The mixture was homogenized using an Ultra-Turrax homogenizer (IKA Werke, Labortechnik, Staufen, Germany) for $2 \mathrm{~min}$, followed by ultrasonication for $30 \mathrm{~min}$. The ultrasonic bath (MRC Scientific Instruments, Holon, Israel) is equipped with a digital control system of sonication time, temperature and frequency. The extraction was performed at a constant frequency of $40 \mathrm{kHz}$, at a constant power of $100 \mathrm{~W}$. Cold water was added to maintain a constant temperature $\left(40 \pm 1{ }^{\circ} \mathrm{C}\right)$ in the ultrasonic bath. After centrifugation at $8000 \times g$ for $10 \mathrm{~min}$ at $4{ }^{\circ} \mathrm{C}$, the residue was re-extracted with $10 \mathrm{~mL}$ of $n$-hexan:acetone solutions $\left(3: 1, v \cdot v^{-1}\right)$ and the extraction was repeated four times. The supernatant was then concentrated under reduced pressure at $40{ }^{\circ} \mathrm{C}$ to dryness (AVC 2-18, Christ, UK). In order to be characterized in terms of phytochemicals and antioxidant activity, the extract was dissolved in a ratio of $1 \mathrm{mg} \cdot \mathrm{mL}^{-1}$ in the extraction solvent and filtered through $0.45 \mu \mathrm{m}$ membranes.

\subsection{Supercritical Fluid $\mathrm{CO}_{2}$ Extraction}

The pilot-plant extraction system (Natex, Prozesstechnologie GesmbH, Austria, Fabr. no. 10-023/2011) designed with a $2.0 \mathrm{~L}$ cylinder extraction vessel and two separators (S40 and S45) each with $1.5 \mathrm{~L}$ capacity were used for the supercritical $\mathrm{CO}_{2}$ extractions of the powdered lavender. Extraction was performed in multiple batches and the extractor basket was filled with $\sim 0.400 \mathrm{~kg}$ of powdered lavender flowers for each extraction. During extraction, the $\mathrm{CO}_{2}$ was constantly chilled to remain liquid and recirculated. The solvent was brought to supercritical conditions at $7.38 \mathrm{MPa}$ and a mass flow rate of $19.061 \mathrm{~kg} / \mathrm{h}$, as indicated by the data sheets from ABB software (ABB Mannheim, Germany). For all extractions the temperature in extraction vessel and the first separator (S40 for 
collection of heavy compounds) was set at $60{ }^{\circ} \mathrm{C}$. Two extraction conditions were applied, $30 \mathrm{MPa}$ and $40 \mathrm{MPa}$ for $60 \mathrm{~min}$ and $120 \mathrm{~min}$. In order to separate the fractions with different compositions, the pressure in the first separator (S40) was maintained at $15 \mathrm{MPa}$, while in the second separator (S45 that collected volatiles) decompression up to recirculation pressure of $5 \mathrm{MPa}$ was set at the temperature of $25^{\circ} \mathrm{C}$ [16]. At the end of each extraction, the decompression of the separators produced the extracts which were collected in dark bottles and kept under refrigeration temperature until further use in experiments.

\subsection{Phytochemicals Measurements}

\subsubsection{Chlorophylls and Carotenoids Measurements}

For estimating the chlorophyll and carotenoid contents, the absorbance was measured at $645 \mathrm{~nm}, 663 \mathrm{~nm}$ and $470 \mathrm{~nm}$, using a spectrophotometer (Biochrom Libra S22 UV/Vis, Cambridge, United Kingdom). In order to calculate Chlorophyll $a$, Chlorophyll $b$, total Chlorophyll and total carotenoids, Arnon's equations were used, as follow:

$$
\begin{gathered}
\text { Chlorophyll } a=0.0127 \times \mathrm{A}_{663}-0.00269 \times \mathrm{A}_{645} \\
\text { Chlorophyll } b=0.0229 \times \mathrm{A}_{645}-0.00468 \times \mathrm{A}_{663} \\
\text { Total Chlorophyll }=0.0202 \times \mathrm{A}_{645}+0.00802 \times \mathrm{A}_{663} \\
\text { Carotenoids }=\left(1000 \times \mathrm{A}_{470}-2.13 \mathrm{Chl} a-97.63 \mathrm{Chl} b\right) / 209
\end{gathered}
$$

The results were expressed as mg per g of dry weight (mg/g D.W.) [16].

\subsubsection{Determination of Total Polyphenolic Content}

The total phenol content (TPC) was determined using Folin-Ciocalteu reagent. In brief, $1 \mathrm{~mL}$ of Folin-Ciocâlteu reagent was added to $0.1 \mathrm{~mL}$ of ethanolic extract, followed by addition of $0.8 \mathrm{~mL}$ of sodium carbonate $(6 \%)$ and $1 \mathrm{~mL}$ of distilled water. After incubation for $30 \mathrm{~min}$, the absorbance was measured at $765 \mathrm{~nm}$ using a spectrophotometer (Biochrom Libra S22 UV/Vis, Cambridge, United Kingdom). Gallic acid was used as the standard and the results were expressed in mg of gallic acid equivalents (GAE) per g D.W. [16].

\subsubsection{Determination of Total Flavonoids Content}

Total flavonoids content (TFC) was determined by adding $1 \mathrm{~mL}$ of distilled water and $0.075 \mathrm{~mL}$ of sodium nitrite $(5 \%)$ to $0.25 \mathrm{~mL}$ of ethanolic extract solution. After incubation for $5 \mathrm{~min}$ in the dark at room temperature, $0.15 \mathrm{~mL}$ of $\mathrm{AlCl}_{3} 10 \%, 0.5 \mathrm{~mL}$ of sodium chloride $(1 \mathrm{M})$ and $1 \mathrm{~mL}$ of distilled water was added and the mixture was further incubated for $10 \mathrm{~min}$ in the dark at room temperature. The absorbance was measured at $510 \mathrm{~nm}$ against a blank sample using a spectrophotometer (Biochrom Libra S22 UV/Vis, Cambridge, United Kingdom). Catechin was used as the standard and the results were expressed in $\mathrm{mg}$ of catechin equivalents (CE) per g D.W. [16].

\subsubsection{Fatty Acids Analysis}

Fatty acid methyl esters (FAMEs) of the total lipids were derivatized by acid-catalyze transesterification using 1\% sulphuric acid in methanol [17]. Lipids (1 mg) were re-suspended in $1 \mathrm{~mL}$ toluene in a Pyrex tube fitted with a condenser. Two milliliters of methanolic $\mathrm{H}_{2} \mathrm{SO}_{4}(1 \% v / v)$ were added, and the mixture was refluxed for $2 \mathrm{~h}$ at $80^{\circ} \mathrm{C}$. Water $(5 \mathrm{~mL})$ containing potassium chloride $\left(5 \% ; w \cdot v^{-1}\right)$ was added, and the transmethylated fatty acids extracted with hexane $(2 \times 5 \mathrm{~mL})$ using Pasteur pipettes to separate the layers. The hexane layer was washed with water $(4 \mathrm{~mL})$ containing $2 \%$ potassium bicarbonate and dried over anhydrous sodium sulphate. Finally, the solution was filtered and the solvent was removed under reduced pressure in a rotary film evaporator. FAMEs were 
analyzed with a gas-chromatograph (GC) coupled with a mass spectrometer (MS), PerkinElmer Clarus 600 T GC-MS (PerkinElmer, Inc., Shelton, CT, USA) as described by [17]. The GC column was a Supelcowax 10 (60 $\mathrm{m} \times 0.25 \mathrm{~mm}$ i.d., $0.25 \mu \mathrm{m}$ film thickness; Supelco Inc., Bellefonte, PA, USA.). The oven temperature was set at $140{ }^{\circ} \mathrm{C}$, then ramped to $220^{\circ} \mathrm{C}$ at $7{ }^{\circ} \mathrm{C} / \mathrm{min}$, and held at $220^{\circ} \mathrm{C}$ for $23 \mathrm{~min}$. The injection volume was $0.5 \mu \mathrm{l}$ (split ratio of $1: 24$ ) and the injector was set at $210^{\circ} \mathrm{C}$. Helium was used as the carrier gas with a constant flow rate of $0.8 \mathrm{~mL} \cdot \mathrm{min}^{-1}$. Mass spectra (E.I., positive ion electron impact mode) were recorded at $70 \mathrm{eV}$ and using a trap current of $100 \mu \mathrm{A}$ with a source temperature of $150{ }^{\circ} \mathrm{C}$. The MS was scanned from $m / z 22$ to 395 for all GC-MS experiments. The FAMEs were identified by comparing their retention times with those of known standards (37 components FAME Mix, Supelco no. 47885-U) and the resulting mass spectra to those in our database (NIST MS Search 2.0). The concentration of each fatty acid was calculated as peak area percentage of total fatty acids.

\subsubsection{Determination of Volatile Profile Using ITEX/GC-MS Technique}

The extraction of volatile compounds from the lavender extracts was performed using in-tube extraction technique (ITEX) as described in our previous work [18] using $0.1 \mathrm{~g}$ of extract. The analysis of volatile compounds was carried out on a GCMS QP-2010 (Shimadzu Scientific Instruments, Kyoto, Japan) model gas chromatograph-mass spectrometer. The volatile compounds were separated on a Zebron ZB-5ms capillary column of $30 \mathrm{~m} \times 0.25 \mathrm{~mm}$ i.d and $0.25 \mu \mathrm{m}$ film thickness. The carrier gas was helium $1 \mathrm{~mL} \cdot \mathrm{min}^{-1}$ and the split ratio $1: 100$. The column oven temperature program was $50{ }^{\circ} \mathrm{C}$ (hold for $2 \mathrm{~min}$ ) to $160{ }^{\circ} \mathrm{C}$ at $4{ }^{\circ} \mathrm{C} / \mathrm{min}$ to $250{ }^{\circ} \mathrm{C}$ at $15{ }^{\circ} \mathrm{C} / \mathrm{min}$ and maintained for $10 \mathrm{~min}$. The injector, ion-source and interface temperatures were set at $250{ }^{\circ} \mathrm{C}$. The MS detection used for this qualitative analysis was performed on a quadrupole mass spectrometer operating in full scan $(40-500 \mathrm{~m} / \mathrm{z}$ ) electron impact (EI) at ionization energy of $70 \mathrm{eV}$. The volatile compounds were tentatively identified by first comparing the obtained mass spectra of each chromatographic peak to NIST27 and NIST147 mass spectra libraries (considering a minimum similarity of 85\%) and then whenever possible by comparison with retention indices drawn from $[19,20]$ (for columns with a similar stationary phase to the ZB-5ms column). This technique offers a qualitative assessment of volatile compounds, so the relative percentage of each compound was estimated as a fraction of its integrated ion area from total ion chromatograms (TIC) area (100\%).

\subsection{Antioxidant Activity}

The DPPH radical scavenging assay was conducted according to the method of Guo et al. [21] with slight modification. Briefly, $0.1 \mathrm{~mL}$ of extract was mixed with $3.9 \mathrm{~mL}$ of DPPH methanolic solution $\left(1.5 \times 10^{-4} \mathrm{M}\right)$. The mixture was shaken vigorously and stored for $30 \mathrm{~min}$ in the dark at approximately $25{ }^{\circ} \mathrm{C}$. The absorbance of the reaction mixture was then measured at $515 \mathrm{~nm}$ using a UV-Vis spectrophotometer (Biochrom Libra S22 UV/Vis, Cambridge, United Kingdom). The antioxidant activity was expressed as mMol Trolox/g D.W. using a calibration curve.

\subsection{Microencapsulation of the Extracts}

The two extracts were encapsulated in different polymers, as follows: the UAE dissolved in vegetable oil were encapsulated in two variants of agar (AA), carboxymethyl cellulose (CMC) and acacia gum (AG). The AA was mixed with CMC (variant 1) and AG (variant 2) at ratio of 1:1. The AA solutions with a total solid content of $2 \%\left(w \cdot w^{-1}\right)$ were prepared by mixing with homogenizer at $650 \mathrm{rpm}$ for $3 \mathrm{~h}$. In addition, CMC and AG, with a total solid content of $1 \%\left(w \cdot w^{-1}\right)$ were prepared through homogenization at $650 \mathrm{rpm}$ for $6 \mathrm{~h}$. Each variant was allowed to stand at $40{ }^{\circ} \mathrm{C}$ and $450 \mathrm{rpm}$ for $30 \mathrm{~min}$.

Before microencapsulation, the S40 and S45 extracts were mixed. The SCE was microencapsulated in a combination of AA, whey protein isolate (WPI), whey protein hydrolysates (WPH) and casein $(\mathrm{CN})$. AA was mixed with WPI and WPH (variant 3) and WPI and CN (variant 4) at ratio of 1:1. The AA 
solutions were prepared as described above. In addition, WPI, WHP and CN solutions, with a total solid content of $1 \%\left(w \cdot w^{-1}\right)$ were prepared by using homogenization at $650 \mathrm{rpm}$ for $4 \mathrm{~h}$.

All coating solutions were kept overnight in the refrigerator at $4-8{ }^{\circ} \mathrm{C}$, to obtain full hydration. An amount of 5.0 g extracts, weighed via precision balance, was dissolved in $20 \mathrm{~mL}$ vegetable oil and further added to the coating mixtures. In order to obtained capsules, the mixtures were homogenized by a high-speed homogenizer (IKA T25 digital Ultra-Turrax, Selangor, Malaysia) at 10,000 rpm for $10 \mathrm{~min}$. The $\mathrm{pH}$ of the emulsions was brought to 3.75 using $0.1 \mathrm{~N} \mathrm{HCl}$ to attain maximum complex coacervation. After this, the internal temperature of the reaction vessel was lowered to $4 \pm 1^{\circ} \mathrm{C}$ using ice water, followed by separation of coacervates. The samples were further frozen at $-70{ }^{\circ} \mathrm{C}$, and the ice crystals were then removed by freeze-drying (CHRIST Alpha 1-4 LD plus, Germany) at $-42{ }^{\circ} \mathrm{C}$ under a pressure of $0.10 \mathrm{mBar}$ for $48 \mathrm{~h}$. Finally, the powders were collected and packed in metalized bags and stored in the freezer at $-20^{\circ} \mathrm{C}$ for later analyses. Each experiment was duplicated.

\subsection{Microencapsulation Efficiency and Powders Characterization}

The microencapsulation efficiency (ME) was estimated for all the compounds measured when characterizing the extracts, namely chlorophylls $a$ and $b$, carotenoids, polyphenolics, and flavonoids. For the evaluation of the phytochemical in the powder, $200 \mathrm{mg}$ of powder was accurately weighed and subjected to extraction with $10 \mathrm{~mL}$ of $n$-hexane:acetone $\left(3: 1, w \cdot v^{-1}\right)$. The mixture was homogenized using an Ultra-Turrax homogenizer (IKA Werke, Labortechnik, Staufen, Germany) for 5 min, followed by ultrasonication for $30 \mathrm{~min}$ at $40 \pm 2{ }^{\circ} \mathrm{C}$. After centrifugation at $8000 \times g$ for $10 \mathrm{~min}$, the supernatant was used for measuring the phytochemicals concentration at selected wavelengths.

The concentration of above-mentioned compounds was used for estimating the encapsulation efficiency using the following formula (Equation (5)):

$$
\operatorname{ME}(\%)=\frac{\left(C_{e}-C_{s}\right)}{C_{e}} \times 100
$$

where $M E \%$ corresponds to the microencapsulation efficiency, $C_{i}$ to the initial concentration of the bioactives in the extract and $C_{f}$ to the concentration of bioactives in the resulting supernatant.

\subsection{Confocal Laser Scanning Microscopy}

A Zeiss LSM 710 confocal laser system was used for the investigations and the 3D images were captured and analyzed by the ZEN 2012 SP1 software (black edition). The technical specifications of the used equipment are: diode laser $(405 \mathrm{~nm})$, Ar-laser $(458,488,514 \mathrm{~nm})$, diode pumped solid state laser $(561 \mathrm{~nm})$ and HeNe-laser (633 nm), AxioObserver Z1 inverted microscope, 40× apochromatic objective (numerical aperture 1.4) and the FS49, FS38 and FS15 filters. To capture the autofluorescence of the native powders, the emission was measured at wavelength between $405-633 \mathrm{~nm}$. In order to acquire the images, the microparticles were stained with two dyes: 4',6-diamidino-2-phenylindole $(1 \mu \mathrm{g} / \mathrm{mL})$ and Red Congo $(40 \mu \mathrm{M})$, in a ratio 3:1:1. To increase the signal-to-noise ratio, the frame average of eight scans was used.

\subsection{Sizing the Particles of the Microencapsulated Powders}

The powders resulted through freeze-drying were suspended in distilled water and homogenized for $60 \mathrm{~min}$ at $20 \pm 1^{\circ} \mathrm{C}$ using a magnetic stirrer. The particle size distributions were further determined by measuring the intensity of the light scattered by the laser beam, when passing through the complete hydrated sample. The particle size measurements were performed by means of the PA-200G Wet Laser Particle Size Analyser (MRC, Holon, Israel). The dispersing medium used for particle size measurements was distilled water. The particle size was expressed both as the surface area mean (D [2,3] or Sauter Mean Diameter) and the volume moment mean (D [3,4] or De Brouckere Mean 
Diameter). Moreover, particle size distribution was presented as maximum diameter bellow which $10 \%$ (D10), 50\% (D50) and 90\% (D90) of the samples volume exist.

\subsection{Antimicrobial Activity}

The method described by Cortes-Zavaleta et al. [22] was used to analyze the antimicrobial activity against three spoilage microorganisms, such as: Aspergillus niger MIUG M5, Penicillium expansum MIUG M11 and Bacillus subtilis MIUG B1 that belong to the Microbial Collection of Dunarea de Jos University, Galați, Romania. An amount of $0.5 \mathrm{~g}$ of each variant was homogenized with $45 \mathrm{~mL}$ of sterile potato dextrose agar (PDA) or plate count agar (PCA) medium, cooled down at $42{ }^{\circ} \mathrm{C}$ and poured into Petri dishes. The plates were centrally inoculated with $5 \mu \mathrm{L}$ spore suspension with a final concentration of $1 \times 10^{6}$ spores/mL and incubated at $25^{\circ} \mathrm{C}$ for 5 days (for molds) and at $37^{\circ} \mathrm{C}$ for $48 \mathrm{~h}$ (for bacteria). Control plates containing PDA and PCA media mixed with sterile distillate water in the same proportions as above were also prepared and inoculated. After the incubation period, the area of the growth in both treated $\left(\mathrm{A}_{\mathrm{T}}\right)$ and control $\left(\mathrm{A}_{\mathrm{C}}\right)$ plates were determined from the mean perpendicular diameter measurements assuming a circular growth. The inhibition ratio (IR) was calculated using the following formula (6):

$$
\operatorname{IR}(\%)=\frac{A_{C}-A_{T}}{A_{C}} \times 100
$$

\subsection{Cell Culture and Treatment}

For cell culture experiments, a mouse fibroblasts cell line (NCTC clone L929, ECACC, Sigma-Aldrich, Germany) was used. Cells were cultured in Minimum Essential Medium (MEM) supplemented with $10 \%\left(v \cdot v^{-1}\right)$ fetal calf serum (FCS), $2 \mathrm{mM}$ L-glutamine and $1 \%\left(v \cdot v^{-1}\right)$ antibiotic mixture (penicillin-streptomycin-neomycin), in a humidified atmosphere with $5 \% \mathrm{CO}_{2}$, at $37{ }^{\circ} \mathrm{C}$, until subconfluence. Trypsinized cells were seeded in 96-well microplates, at a density of $4 \times 10^{4}$ cells $/ \mathrm{mL}$ and allowed to adhere by incubation at $37^{\circ} \mathrm{C}$, in humidified atmosphere with $5 \% \mathrm{CO}_{2}$, for $24 \mathrm{~h}$. Then, the culture medium was replaced with fresh medium containing different concentrations of sterilized samples ranging from $10-1000 \mu \mathrm{g} / \mathrm{mL}$. The plates were incubated at $37^{\circ} \mathrm{C}$ under standard conditions, for $24 \mathrm{~h}$ and $48 \mathrm{~h}$, respectively. Cells cultivated in normal culture medium were used as negative control culture.

\subsection{In Vitro Cytotoxicity Test}

Cell viability in treated cultures was evaluated by Neutral red (NR) assay, as previously described [23]. Briefly, at the end of each incubation period, the culture medium was removed from each well and the cells were incubated with $50 \mu \mathrm{g} / \mathrm{mL} \mathrm{NR}$ solution, at $37^{\circ} \mathrm{C}$, for $3 \mathrm{~h}$. After cell washing, the incorporated dye was released in $1 \%\left(v \cdot v^{-1}\right)$ acetic acid solution in $50 \%\left(v \cdot v^{-1}\right)$ ethanol by gentle shaking, for $15 \mathrm{~min}$. The amount of uptaken dye was directly proportional to the number of viable cells. The optical density was measured at $540 \mathrm{~nm}$ in a Sunrise microplate reader (Tecan, Austria). The results were reported as percentage relative to the control culture, considered $100 \%$ viable.

\subsection{Cell Morphology}

After $48 \mathrm{~h}$ of cultivation in the presence of samples, cell morphology was observed in images acquired using a phase-contrast inverted microscope Axio Observer D1 equipped with digital camera (Carl Zeiss, Germany).

\subsection{Testing the Microencapsulated Powder in Food Matrices}

The ice cream was prepared using a classic recipe, where variants 1 and 2 were added in milk as an ingredient. The recipe involved the use of condensed milk, cream, sugar, and microencapsulated powder in ratio of $1 \%$. The ice cream recipe involved a mixing step (5 min) of milk with sugar and variants 1 and 2 . The cream was obtained by foaming, after which all the ingredients were 
mixed. The ice cream mix was introduced at $-18^{\circ} \mathrm{C}$ for $6 \mathrm{~h}$, with homogenization in the first $2 \mathrm{~h}$ at half-hourly intervals.

For the macaroons, the recipe involved the use of the walnuts, almonds, sugar, egg whites and variants 3 and 4 in ratio of $1 \%$. The first stage consisted in crushing the nuts and almonds. The egg whites were mixed with sugar until a stable foam was obtained. All components were mixed well together with variants 3 and 4, after which the macaroons were formed, each weighting of $20 \mathrm{~g}$. The macaroons were obtained by heat treatment at $175^{\circ} \mathrm{C}$ for $15 \mathrm{~min}$ in a convection oven. For each type of product, a control sample was obtained. The ice cream samples were coded $I_{M}, I_{1}$ and $I_{2}$, whereas macaroons were coded as $\mathrm{M}_{\mathrm{M}}, \mathrm{M}_{3}$ and $\mathrm{M}_{4}$, respectively.

\subsection{Statistical Analysis of Data}

All experimental measurements were performed at least in triplicate, and the results are presented as mean value \pm standard deviation (SD). One-way analysis of variance (ANOVA) and Tukey's test with a 95\% confidence interval was applied using Minitab 18 software to identify significant differences among results. Statistical analysis of the cell culture results was performed using two-tailed, two-sample equal variance Student's $t$-test. Differences were considered statistically significant at $p \leq 0.05$ and $p \leq 0.01$ as minimal levels of significance.

\section{Results and Discussion}

\subsection{Total Phytochemical Characterization of the Lavender Flowers Extracts}

In our study, two extracts were obtained with different total phytochemicals profiles, thus aligning with numerous screening studies of various plant materials that have been performed in order to find naturally occurring antioxidants to be used in food or medicinal preparations, as replacements for potentially harmful synthetic additives [24]. Therefore, the two fractions resulting from SCE were mixed and characterized in terms of chlorophylls, carotenoids, polyphenolics, flavonoids and antioxidant activity. For volatile and fatty acids, the two fractions were analyzed separately. The UAE showed a chlorophyll $a$ and $b$ content of $2.10 \pm 0.08 \mathrm{mg} / \mathrm{g}$ D.W and $0.69 \pm 0.02 \mathrm{mg} / \mathrm{g}$ D.W, respectively, whereas the content in total carotenoids was $0.42 \pm 0.01 \mathrm{mg} / \mathrm{g}$ D.W. The SCE displayed higher chlorophyll $a$ and $b$ content of $5.22 \pm 0.12 \mathrm{mg} / \mathrm{g}$ D.W. and $2.95 \pm 0.16 \mathrm{mg} / \mathrm{g}$ D.W, whereas the carotenoids content was $18.24 \pm 0.04 \mathrm{mg} / \mathrm{g}$ D.W.

The TPC had values of $23.61 \pm 0.75 \mathrm{mg}$ GAE/g D.W. in UAE and almost four times more in SCE $(80.95 \pm 0.67 \mathrm{mg} \mathrm{GAE} / \mathrm{g}$ D.W.). The same trend was observed in TFC, with values of $19.45 \pm 0.45 \mathrm{mg}$ CE/g D.W. and $34.02 \pm 0.51 \mathrm{mg}$ CE/g D.W., respectively.

The GC-MS analysis of the extracts led to the identification of 44 and 26 volatile compounds in SCE and UAE, respectively. Table 1 shows the main chemical composition of the extracts, revealing the presence of seven main compounds in SCE ( $\beta$-linalool, eucalyptol, linalool acetate, $\beta$-trans-ocimene, and limonene) (Figure S1 in Supplementary Materials), whereas in UAE the main chemical showed the presence of seven main compounds (linalool acetate, $\beta$-linalool, 6-methyl-2-(2-oxiranyl)-5-hepten-2-ol, linalool oxide, lavandulyl acetate and camphor). 
Table 1. Volatile compounds in lavender of lavender extracts.

\begin{tabular}{|c|c|c|c|}
\hline \multirow{2}{*}{ Compound Name } & \multicolumn{3}{|c|}{$\%$ of Total Peak Areas } \\
\hline & SCE (S40) & SCE (S45) & UAE \\
\hline 2-Pentanone, 4-hydroxy-4-methyl- & - & - & $9.24 \pm 0.89 *$ \\
\hline 2(5H)-Furanone, 5.5-dimethyl- & - & - & $0.37 \pm 0.10$ \\
\hline 1-Hexanol & $0.05 \pm 0.01$ & $0.08 \pm 0.01$ & - \\
\hline Tricyclo[2.2.1.0(2,6)]heptane, 1,7,7-trimethyl- & $0.03 \pm 0.01$ & $0.13 \pm 0.02$ & - \\
\hline Origanene & $0.06 \pm 0.01$ & $0.15 \pm 0.02$ & - \\
\hline$\alpha$-Pinene & $0.30 \pm 0.02$ & $0.77 \pm 0.04$ & - \\
\hline 3-Heptanone, 6-methyl- & $0.11 \pm 0.05$ & $0.11 \pm 0.01$ & - \\
\hline Heptane, 2.5.5-trimethyl- & & & $0.24 \pm 0.17$ \\
\hline Camphene & $0.77 \pm 0.09$ & $1.97 \pm 0.11$ & - \\
\hline u.i. & $0.17 \pm 0.02$ & $0.86 \pm 0.11$ & - \\
\hline 2-Thujene & $0.04 \pm 0.01$ & $0.08 \pm 0.01$ & - \\
\hline 4(10)-Thujene (Sabinen) & $0.10 \pm 0.01$ & $0.47 \pm 0.02$ & - \\
\hline$\beta$-Pinene & $0.25 \pm 0.05$ & $0.41 \pm 0.03$ & - \\
\hline 1-Octen-3-ol & $0.20 \pm 0.05$ & $0.17 \pm 0.01$ & - \\
\hline 3-Octanone & $1.30 \pm 0.07$ & $1.09 \pm 0.05$ & $0.30 \pm 0.10$ \\
\hline$\beta$-Myrcene & $1.34 \pm 0.10$ & $1.32 \pm 0.11$ & $2.83 \pm 0.45$ \\
\hline Butanoic acid, butyl ester & $0.15 \pm 0.01$ & $0.18 \pm 0.01$ & - \\
\hline u.i. & $0.09 \pm 0.01$ & $0.10 \pm 0.01$ & - \\
\hline Acetic acid, hexyl ester (1-Hexyl acetate) & $0.85 \pm 0.08$ & $0.80 \pm 0.11$ & - \\
\hline$\alpha .-$ Terpinene & $0.08 \pm 0.01$ & $0.11 \pm 0.01$ & - \\
\hline p-Cymene & $0.83 \pm 0.10$ & $1.16 \pm 0.41$ & $0.23 \pm 0.01$ \\
\hline Limonene & $3.48 \pm 0.54$ & $4.87 \pm 0.58$ & $0.97 \pm 0.15$ \\
\hline Eucalyptol & $16.72 \pm 0.98$ & $17.62 \pm 1.20$ & $2.10 \pm 0.08$ \\
\hline$\beta$-trans-Ocimene & $4.02 \pm 0.45$ & $5.13 \pm 0.74$ & $1.56 \pm 0.02$ \\
\hline$\beta$-cis-Ocimene & $1.58 \pm 0.23$ & $1.60 \pm 0.12$ & $1.48 \pm 0.09$ \\
\hline$\gamma$-Terpinene & $0.16 \pm 0.08$ & $0.36 \pm 0.11$ & - \\
\hline 6-Methyl-2-(2-oxiranyl)-5-hepten-2-ol & $3.98 \pm 0.23$ & $3.45 \pm 0.41$ & $6.74 \pm 1.02$ \\
\hline Linalool oxide (fr.1) & $3.04 \pm 0.25$ & $2.66 \pm 0.52$ & $5.76 \pm 0.28$ \\
\hline$\beta$-Linalool & $19.94 \pm 1.01$ & $20.44 \pm 1.20$ & $15.18 \pm 1.20$ \\
\hline Octen-1-ol, acetate & $1.01 \pm 0.05$ & $0.97 \pm 0.11$ & $1.85 \pm 0.07$ \\
\hline 2,4,6-Octatriene, 2,6-dimethyl-, (E, Z)- & $0.71 \pm 0.11$ & $0.58 \pm 0.15$ & $0.18 \pm 0.02$ \\
\hline Camphor & $10.3 \pm 0.74$ & $7.82 \pm 1.21$ & $4.39 \pm 0.23$ \\
\hline Lavandulol & $0.35 \pm 0.11$ & $0.33 \pm 0.08$ & - \\
\hline Borneol & $1.76 \pm 0.25$ & $2.38 \pm 0.54$ & $3.16 \pm 0.78$ \\
\hline 1-Terpinen-4-ol & $1.41 \pm 0.47$ & $1.42 \pm 0.69$ & $1.46 \pm 0.03$ \\
\hline u.i. & & & $1.30 \pm 0.04$ \\
\hline Butanoic acid, hexyl ester & - & 0.37 & - \\
\hline n-Hexyl butanoate & $0.44 \pm 0.11$ & - & - \\
\hline$\alpha$-Terpineol & - & $0.20 \pm 0.01$ & - \\
\hline Isobornyl formate & - & $0.11 \pm 0.01$ & $0.22 \pm 0.01$ \\
\hline Linalool acetate & $18.08 \pm 0.87$ & $15.28 \pm 1.25$ & $25.86 \pm 1.24$ \\
\hline Lavandulyl acetate & $2.63 \pm 0.56$ & $2.13 \pm 0.52$ & $5.62 \pm 0.78$ \\
\hline u.i. & $0.15 \pm 0.08$ & $0.08 \pm 0.01$ & $1.06 \pm 0.06$ \\
\hline 8-Hydroxylinalool & - & - & $2.54 \pm 0.24$ \\
\hline Nerol & $0.14 \pm 0.09$ & $0.11 \pm 0.01$ & $0.53 \pm 0.08$ \\
\hline u.i. ${ }^{* *}$ & $0.38 \pm 0.11$ & $0.24 \pm 0.05$ & $1.17 \pm 0.09$ \\
\hline Caryophyllene & $1.73 \pm 0.12$ & $1.20 \pm 0.02$ & $1.86 \pm 0.08$ \\
\hline$\alpha$-Bergamotene & $0.08 \pm 0.01$ & $0.05 \pm 0.01$ & - \\
\hline$\beta$-Farnesene & $0.62 \pm 0.22$ & $0.49 \pm 0.01$ & $0.43 \pm 0.09$ \\
\hline$\gamma$-Muurolene & $0.09 \pm 0.01$ & - & - \\
\hline u.i. & $0.15 \pm 0.04$ & $0.17 \pm 0.01$ & $0.98 \pm 0.14$ \\
\hline Acetic acid. hexyl ester & - & - & $0.39 \pm 0.17$ \\
\hline
\end{tabular}

*-standard deviation, ${ }^{* *}$ unidentified., SCE-supercritical fluid extracts obtained in separator $S 40$ and 45 , respectively, UAE-ultrasound-assisted extract. 
In both extracts, the main volatile compounds represented more than $71 \%$ of the extract composition. No differences in volatile profiles were found between S40 and S45 fractions, but significant differences occurred between the two types of extracts, SCE and UAE, respectively. Although present in small proportions, SCE fractions are richer in volatile compounds than the UAE. For example, the S40 and S45 fractions contained $\alpha$-pinene, 3-heptanone, 6-methyl-, camphene, sabinene, $\beta$-pinene, 1-Octen-3-ol etc. However, the UAE contained about two times higher quantities of $\beta$-myrcene, 6-Methyl-2-(2-oxiranyl)-5-hepten-2-ol, linalool oxide (fr.1) and octen-1-ol, acetate and a significant lower proportion of camphor. Significant differences were found in limonene, eucalyptol, $\beta$-trans-ocimene, $\beta$-linalool proportions, with a higher proportion in S45 and less in UAE. Regarding the proportions of linalool acetate, the UAE contained the highest amount $(25.86 \pm 1.24 \%)$, followed by S40 fraction $(18.08 \pm 0.87 \%)$ and S45 $(15.28 \pm 1.25 \%)$.

The chemical composition of lavender and lavandin essential oils is characterized by the presence of terpenes (e.g., linalool and linalyl acetate) and terpenoids (e.g., 1,8-cineole), which are mainly responsible for the characteristic flavor and the biological and therapeutic properties [25].

The effects of three operating conditions of supercritical $\mathrm{CO}_{2}$ extraction, namely pressure, temperature and time, on yield, chemical composition and antioxidant activity of lavender essential oil were investigated by Danh et al. [16]. These authors suggested that four major compounds were detected in all extracts, namely linalool $(\sim 43 \%)$, linalyl acetate $(\sim 23 \%)$, camphor $(\sim 8 \%)$ and borneol ( $\sim 6.6 \%)$, which combined made up about $80 \%$ of the oil yields.

Da Porto et al. [14] used three methods, such as hydrodistillation, SCE and UAE to comparatively evaluate the flavor compound from Lavandula angustifolia L. extracts. These authors suggested linalool and linalyl acetate as the principal components in the extracts, with higher concentrations of linalool, camphor, linalyl acetate and (E)-caryophyllene in SCE extracts.

Figure S2 in Supplementary Materials shows the typical GC-MS chromatogram, which reveals the presence of seven peaks in SCE (Figure S2a) and eight peaks in UAE (Figure S2b), respectively. The type and ratio of fatty acids identified in the lavender extracts are shown in Table 2.

Table 2. Fatty acid composition (\% of total fatty acids) of lavender extracts.

\begin{tabular}{lccc}
\hline \multicolumn{1}{c}{ Fatty Acids } & SCE (S40) & SCE (S45) & UAE \\
\hline$\alpha$-linolenic acid (18:3n-3) & $31.67 \pm 1.58 *$ & $25.61 \pm 1.25$ & $11.82 \pm 0.55$ \\
Palmitic acid (16:0) & $49.80 \pm 2.31$ & $25.10 \pm 0.87$ & $18.71 \pm 0.80$ \\
Linoleic acid (18:2n-6) & $7.66 \pm 1.02$ & $16.81 \pm 1.05$ & $19.66 \pm 0.85$ \\
Oleic acid (18:1n-9) & $5.37 \pm 0.89$ & $11.35 \pm 0.99$ & $27.21 \pm 1.10$ \\
Stearic acid (18:0) & $1.55 \pm 0.25$ & $8.39 \pm 0.11$ & $13.73 \pm 0.62$ \\
Behenic acid (22:0) & $2.52 \pm 0.12$ & $5.79 \pm 0.35$ & $3.58 \pm 0.20$ \\
Arachidic acid (20:0) & $0.86 \pm 0.16$ & $5.63 \pm 0.52$ & $4.62 \pm 0.25$ \\
Vaccenic acid (18:1n-7) & $0.59 \pm 0.11$ & $1.31 \pm 0.07$ & $0.67 \pm 0.08$ \\
SFAs & $54.73 \pm 1.25$ & $44.91 \pm 1.53$ & $40.64 \pm 1.35$ \\
MUFAs & $5.93 \pm 1.20$ & $12.66 \pm 1.28$ & $27.88 \pm 1.20$ \\
PUFAs & $39.33 \pm 1.48$ & $42.43 \pm 1.87$ & $31.48 \pm 1.35$ \\
$n$-3 PUFAs & $31.67 \pm 1.59$ & $25.61 \pm 0.85$ & $11.82 \pm 0.55$ \\
$n$-6 PUFAs & $7.66 \pm 1.58$ & $16.81 \pm 0.98$ & $19.66 \pm 0.90$ \\
$n$-6/n-3 & 0.24 & 0.66 & 1.66 \\
PUFAs/SFAs & 0.72 & 0.94 & 0.77 \\
\hline
\end{tabular}

Abbreviations: SFAs—saturated fatty acids, MUFAs—-monounsaturated fatty acids, PUFAs—polyunsaturated fatty acids. *-standard deviation.

The fatty acid profile highly depends on the type of extraction and SCE fraction. From Table 2, it can be seen that the S40 fraction presented the highest proportions of $\alpha$-linolenic $(31.67 \pm 1.58 \%)$ and palmitic acids $(49.80 \pm 2.31 \%)$, whereas UAE showed the highest proportion of linoleic $(19.66 \pm 0.85 \%)$, oleic $(27.21 \pm 1.10 \%)$ and stearic acids $(13.73 \pm 0.62 \%)$.

It can be observed that the all extracts accumulate a relative high concentration of polyunsaturated fatty acids (with the highest value of $42.43 \%$ in S45) and lower concentrations of monounsaturated 
fatty acids (with the highest value of $27.88 \pm 1.20 \%$ in UAE and the lowest of $5.93 \pm 1.20 \%$ in S40). The $n-3$ acids had a higher contribution in $S 40(31.67 \pm 1.59 \%)$ compared to $n-6$ acids $(7.66 \pm 1.58 \%)$ and lower in UAE, of $11.82 \pm 0.55 \%$ and $19.66 \pm 0.90 \%$, respectively. Therefore, based on our results, it can be concluded that the extraction method highly influenced the phytochemical profile of the extracts. Thus, only with the exact knowledge of the phytochemical profile and related biological activities, it will be possible to develop a new generation of standardized, multifunctional plant-based formula, fulfilling actual standards for quality, safety and efficiency.

\subsection{Microencapsulation Efficiency}

Usually, health-promoting bioactives, such as carotenoids, polyphenols, polyunsaturated fatty acids etc. are prone to degradation, due to their chemical structure and processing and storage conditions. Encapsulation is a technique that preserves the physicochemical and health-promoting properties associated with bioactive compounds [26], thus promoting protection against environmental conditions and allowing controlled release in target sorption areas. The choice of suitable biopolymers as wall materials is critical to the success of microencapsulation, because the type of wall material is decisive for the physicochemical and morphological properties of the produced powders, affecting the encapsulation efficiency, shelf-life, and the degree of protection of the sensitive core materials [6]. Four variants were tested in our study, by combining agar with two polysaccharides and two proteins. The microencapsulation efficiencies were evaluated for each tested compound and are given in Table 3.

Table 3. Microencapsulation efficiencies for selected phytochemical (\%).

\begin{tabular}{lcccc}
\hline $\begin{array}{c}\text { Selected } \\
\text { Parameter }\end{array}$ & Variant 1 (CMC) & Variant 2 (AG) & Variant 3 (WPI-WPH) & Variant 4 (WPI-CN) \\
\hline Total chlorophylls & $41.97 \pm 1.70^{\mathrm{c}, *}$ & $49.02 \pm 1.33^{\mathrm{b}}$ & $95.22 \pm 1.85^{\mathrm{a}}$ & $94.65 \pm 1.44^{\mathrm{a}}$ \\
Chlorophyll $a$ & $38.87 \pm 1.43^{\mathrm{c}}$ & $44.79 \pm 0.57^{\mathrm{b}}$ & $96.62 \pm 2.87^{\mathrm{a}}$ & $98.01 \pm 1.56^{\mathrm{a}}$ \\
Chlorophyll $b$ & $43.90 \pm 3.56^{\mathrm{c}}$ & $51.79 \pm 2.55^{\mathrm{b}}$ & $90.61 \pm 1.20^{\mathrm{a}}$ & $90.61 \pm 1.36^{\mathrm{a}}$ \\
Total carotenoids & $49.32 \pm 3.16^{\mathrm{b}}$ & $50.14 \pm 2.97^{\mathrm{b}}$ & $94.79 \pm 1.29^{\mathrm{a}}$ & $97.04 \pm 1.20^{\mathrm{a}}$ \\
Total polyphenols & $61.79 \pm 1.98^{\mathrm{b}}$ & $61.92 \pm 1.54^{\mathrm{b}}$ & $93.88 \pm 2.01^{\mathrm{a}}$ & $93.93 \pm 2.01^{\mathrm{a}}$ \\
Total flavonoids & $73.36 \pm 2.87^{\mathrm{c}}$ & $69.82 \pm 1.47^{\mathrm{d}}$ & $90.22 \pm 1.20^{\mathrm{b}}$ & $90.72 \pm 2.47^{\mathrm{a}}$ \\
\hline
\end{tabular}

Values are represented as mean \pm standard errors $\left({ }^{*}\right)$. Superscript values that for the same column do not share the same letter ( $\mathrm{a}, \mathrm{b}, \mathrm{c}$ and $\mathrm{d}$ ) are significantly different at $p<0.05$ based on the Tukey method. Different encapsulants were used, such as: Variant 1-agar and carboxymethyl cellulose, Variant 2-agar and acacia gum, Variant 3-agar and whey protein isolates and whey protein hydrolysates, Variant 4-agar and whey protein isolates and whey protein casein.

From Table 3 it can be seen that the use of proteins as microencapsulation adjuvants along with agar resulted in higher ME for each phytochemical. For example, for chlorophyll $a$, the ME was $70.95 \pm 1.45 \%$, in variant one, $68.57 \pm 2.47 \%$ in variant two, $96.62 \pm 1.84 \%$ and $98.01 \pm 2.51 \%$ in variants three and four, respectively. Variants three and four showed the highest ME values for all the phytochemicals, suggesting that whey proteins and caseins are efficient wall materials.

Kang et al. [6] encapsulated unstable chlorophylls using different blends of gum Arabic (GA) and maltodextrin (MD) (GA-MD ratios of 5:5, 3:7, and 0:10) by spray-drying. These authors reported that an increase in concentration of MD in the wall materials was associated with lower moisture content $(0.56 \%)$, higher encapsulation efficiency $(77.19 \%)$, chlorophyll content (46.78 $\mu \mathrm{g} / \mathrm{g}$ dry powder), degree of crystallinity, and thermal stability of microcapsules.

\subsection{Powders Characterization}

The phytochemical profile of the powders is given in Table 4. A significant different pattern was found for all variants, with higher contents of chlorophylls and carotenoids in variants one and two. Polyphenolics and flavonoids were found in higher concentration in variants three and four, leading to higher antioxidant activity. Kang et al. [6] reported that the chlorophyll content significantly increased with an increase in maltodextrin concentration in wall materials, and varied 
between $34.77 \pm 0.12 \mu \mathrm{g} / \mathrm{D} . \mathrm{W}$. powder and $46.78 \pm 0.14 \mu \mathrm{g} / \mathrm{D} . \mathrm{W}$ powder for gum acacia: maltodextrin ratio of 5:5 and 0:10, respectively.

Table 4. Phytochemical profile of the powders.

\begin{tabular}{|c|c|c|c|c|}
\hline Selected Parameter & $\begin{array}{l}\text { Variant } 1 \\
\text { (CMC) }\end{array}$ & Variant 2 (AG) & $\begin{array}{c}\text { Variant } 3 \\
\text { (WPI-WPH) }\end{array}$ & $\begin{array}{c}\text { Variant } 4 \\
\text { (WPI-CN) }\end{array}$ \\
\hline Total chlorophylls (mg/g D.W.) & $1.54 \pm 0.05^{\mathrm{a}, *}$ & $0.88 \pm 0.03^{b}$ & $0.43 \pm 0.05^{c}$ & $0.27 \pm 1.44^{\mathrm{d}}$ \\
\hline Chlorophyll $a$ (mg/g D.W.) & $0.61 \pm 0.01^{b}$ & $0.68 \pm 0.02^{a}$ & $0.17 \pm 0.07^{c}$ & $0.10 \pm 1.56^{\mathrm{d}}$ \\
\hline Chlorophyll $b$ (mg/g D.W.) & $0.93 \pm 0.10^{b}$ & $1.05 \pm 0.10^{\mathrm{a}}$ & $0.27 \pm 0.02^{c}$ & $0.16 \pm 1.36^{\mathrm{d}}$ \\
\hline Total carotenoids (mg/g D.W.) & $338.70 \pm 24.60^{\mathrm{a}}$ & $339.30 \pm 2.39^{a}$ & $95.00 \pm 1.29^{b}$ & $53.82 \pm 1.20^{\circ}$ \\
\hline Total polyphenols (mg GAE/g D.W.) & $5.17 \pm 0.42^{\mathrm{d}}$ & $5.47 \pm 1.54^{c}$ & $9.71 \pm 2.01^{b}$ & $10.78 \pm 0.10^{\mathrm{a}}$ \\
\hline Total flavonoids (mg CE/g D.W.) & $4.25 \pm 0.87^{c}$ & $3.98 \pm 0.47^{d}$ & $6.61 \pm 1.20^{b}$ & $6.92 \pm 0.92^{\mathrm{a}}$ \\
\hline Antioxidant activity (mMol Trolox/g D.W.) & $2.85 \pm 0.12^{c}$ & $3.44 \pm 0.32^{b}$ & $4.77 \pm 0.26^{\mathrm{a}}$ & $4.80 \pm 0.15^{\mathrm{a}}$ \\
\hline
\end{tabular}

Values are represented as mean \pm standard errors $\left(^{*}\right)$. Superscript values that for the same column do not share the same letter $(\mathrm{a}, \mathrm{b}, \mathrm{c}$ and $\mathrm{d})$ are significantly different at $p<0.05$ based on the Tukey method.

From the data presented in Table 4, it can be concluded that phytochemical profile of the freeze-dried microencapsulated powders highly depends on the phytochemical profile of the extract and wall material. Therefore, the combination of AA with CMC and AG was more effective in retention of carotenoids, whereas combining WPI with WPH and CN led to a higher retention of polyphenols. When comparing WPH and CN, from Table 4 it can be observed that WPH and WPI were more efficient in carotenoid retention.

\subsection{Morphology and Particle Size of the Microencapsulated Powders}

In the native samples obtained through the novel microencapsulating formulas (Figure 1a-d), thin scales with irregular, asymmetric forms were observed, their emission being throughout the whole spectral range due to their complex composition. Nonetheless, the variants one and two seem to have a more uniform distribution of the biologically active compounds inside the microencapsulating biopolymeric matrices.
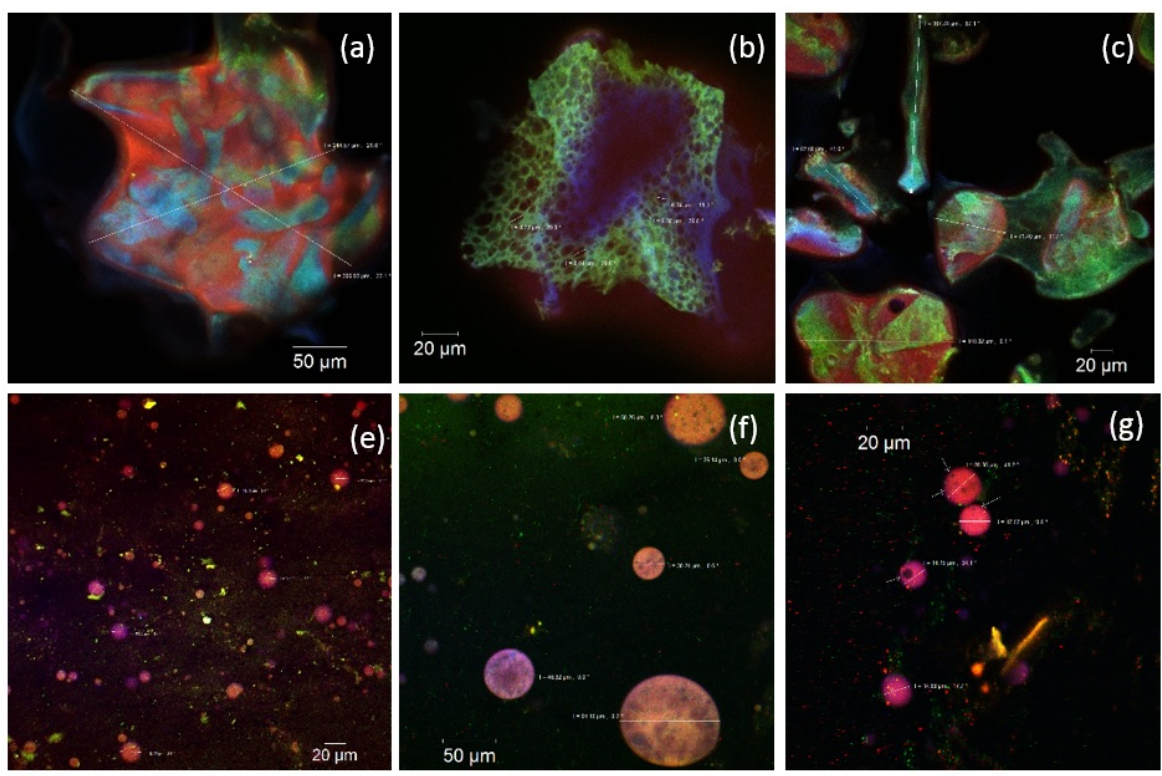
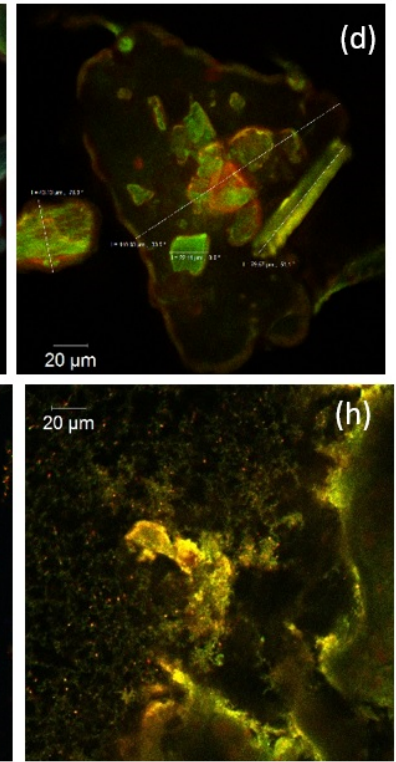

Figure 1. Confocal laser scanning microscopy images of the native variant 1 (a), variant $2(\mathbf{b})$, variant 3 (c), variant 4 (d) microencapsulated powders, and of the stained variant 1 (e), variant 2 (f), variant 3 (g), variant 4 (h) microencapsulated powders.

It is well-known that lavender contains besides lipophilic components (essential oils with high concentrations of alcohols, aldehydes, esters, ketones and sesquiterpenes), hydrophilic compounds 
(phenolic compounds, flavonoids-mainly flavone glycosides, anthocyanins, tannins, etc.) that are responsible for the anti-inflammatory, antibacterial, antifungal, sedative and spasmolytic activity [27]. The particles sizes and their morphology depend on the microencapsulation method and on the component's ratio in the microencapsulation matrix formula. Large scale formations with the average size between 40 and $80 \mu \mathrm{m}$ (Figure 1), with irregular outline and porous structures (like micro-cavities or fissures with 6-8 $\mu \mathrm{m}$ diameters like in Figure $1 \mathrm{~b}$ ) were visualized. Some of them are very large $(244.57-306.93 \mu \mathrm{m})$ such as the ones seen in Figure 1a. The dyed microencapsulated powders revealed the presence of lipophilic compounds in the form of spheroids with different diameters ranging in average between 10 and 30 microns (Figure 1e-h). In variant four, the spheres presented the smallest values, most of them having a diameter smaller than $2 \mu \mathrm{m}$ (Figure $1 \mathrm{~d}$ ). In the other variants, $20 \%$ of the spherosomes had diameters of more than $60 \mu \mathrm{m}$ (Figure 1b). Moreover, within these giant spherosomes one can observe microvesicles (the arrows in Figure $1 b, c$ ), suggesting a possible double encapsulation. The various protein components used in the microencapsulation process usually emit in a wide domain of wavelengths ranging from 550 to $650 \mathrm{~nm}$. They formed a complex matrix in which the lavender's biologically active compounds were encapsulated. Therefore, it can be concluded that CMC (Figure 1f) and WPH (Figure 1g) used for the microencapsulation led to a double encapsulation of the lipophilic compounds with biological value from the lavender extract, although the finest and the most homogeneous powders were obtained when AG (Figure 1e) and CN (Figure 1h) matrices were used.

Knowledge of the particle properties of the microencapsulated powder is important for better understanding and tailoring the quality of the final product. Therefore, in order to distinguish between coarse and fine particulates present in the samples, both $\mathrm{D}[2,3]$ and $\mathrm{D}[3,4]$ were measured. The $\mathrm{D}[2,3]$ is mainly useful for monitoring the presence of fine particles in the mixture, whereas $\mathrm{D}[3,4]$ provides a good estimation of the size of the particles representing the majority of the sample volume. Analyzing the results presented in Table 5, one can see that for all microencapsulated powders the size of the coarser particles is slightly higher compared to the fines.

Table 5. Particle characterization of the microencapsulated powders.

\begin{tabular}{ccccc}
\hline & Variant 1 (CMC) & Variant 2 (AG) & Variant 3 (WPH) & Variant 4 (WPI-CN) \\
\hline $\mathrm{D}[2,3], \mu \mathrm{m}$ & 4.494 & 4.701 & 4.620 & 4.738 \\
$\mathrm{D}[3,4], \mu \mathrm{m}$ & 4.684 & 5.048 & 4.909 & 5.108 \\
$\mathrm{D} 10, \mu \mathrm{m}$ & 3.613 & 3.648 & 3.635 & 3.654 \\
$\mathrm{D} 50, \mu \mathrm{m}$ & 4.497 & 4.608 & 4.563 & 4.629 \\
$\mathrm{D} 90, \mu \mathrm{m}$ & 5.698 & 7.612 & 6.665 & 7.860 \\
\hline
\end{tabular}

D [2,3]-surface area mean; D [3,4]-volume moment mean; D10, D50 and D90-maximum diameter bellow which $10 \%, 50 \%$ and $90 \%$, respectively, of the samples volume exist.

The $\mathrm{D}[2,3]$ values decrease in the following order variant $4>$ variant $2>$ variant $3>$ variant 1 (Table 5). The same trend was observed for the size of the coarse particles present in the microencapsulated powders, D [3,4] values ranging from $4.684 \mu \mathrm{m}$ registered for variant one and $5.108 \mu \mathrm{m}$ for variant four. The largest variation of the particle size was registered in case of variant four, when $80 \%$ of sample volume had particle diameters ranging from 3.654 to $7.860 \mu \mathrm{m}$. On the other hand, the most uniform microencapsulated powder in terms of particle size was variant one with the narrowest D10-D90 range of 3.613-5.698 $\mu \mathrm{m}$.

\subsection{Antimicrobial Activity}

The highest antimicrobial activity of $100 \%$ was found for variants one and two against Penicillium expansum MIUG M11 and Bacillus subtilis MIUG B1. The most resistant fungal strain turned out to be Aspergillus niger MIUG M5 for all four variants, showing no or lower antifungal activity ( 0 up to $6.52 \%$ ). The higher antimicrobial activity of variants one and two may be associated with the higher contents of carotenoids, and probably free fatty acids. There are numerous studies reporting the antimicrobial potential of carotenoids on different spoilage and pathogen microorganisms. 
Most probably, the mechanism of antimicrobial activity involves the precipitation of membrane proteins, resulting in microbial cell lysis. However, given the inhibition ratio results, the biophysical and biochemical effects of fatty acids on the molecular structure of the cytoplasmic membrane might have potential. The hydrocarbon chain of added long-chain fatty acids might be inserted into the phospholipid bilayer of the membrane, thus increasing the destabilization of the membrane, as explained by Kitahara et al. [28]. The higher antimicrobial activities of the variants one and two may be a synergistic result of the fatty and carotenoid content. These results are in agreement with Czerwińska and Szparaga [29], who reported the antimicrobial activity of some aqueous extracts of Lavandula vera L. against Bacillus subtilis, Aspergillus glaucus and Aspergillus niger. Bacillus subtilis and Aspergillus niger were the most resistant strains.

In conclusion, the significant antimicrobial effect of variants one and two against selected strains of molds and bacteria may be attributed to the dominant presence of carotenoids in the UAE samples, in addition to the complexity of the fatty acid's compositions and the microbial skeletons characteristics [30]. Moreover, the existence of unsaturated fatty acids in the both types of extracts has a powerful effect on the antimicrobial activity due to increased cell membrane permeability [31]. Nevertheless, our results showed noticeable antibacterial effect mainly due to the presence of carotenoids and chlorophyll.

\subsection{In Vitro Cytotoxicity}

The samples' cytotoxicity was evaluated in L929 fibroblast cell culture by NR assay. The results obtained for cell viability at $24 \mathrm{~h}$ (a) and $48 \mathrm{~h}$ (b) of cultivation are presented in Figure 2.

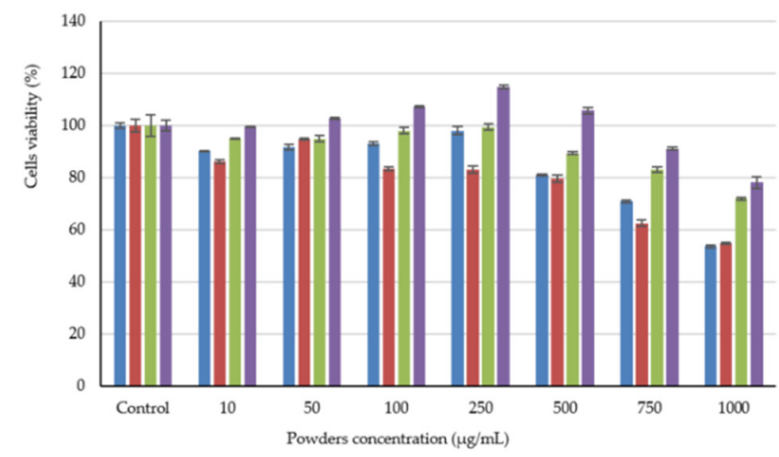

(a)

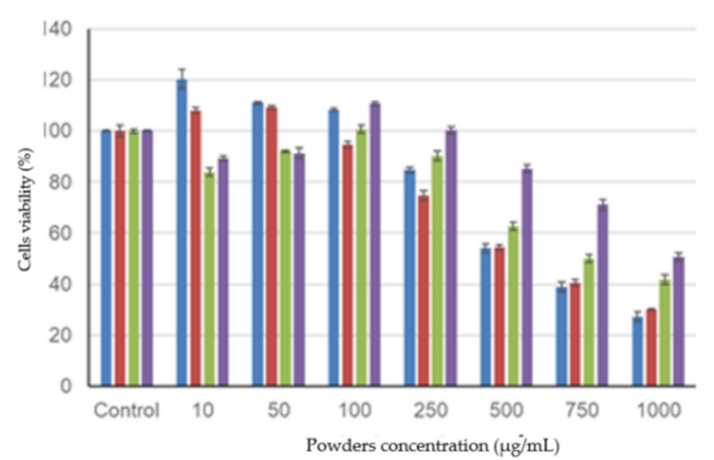

(b)

Figure 2. Cell viability on L929 fibroblasts cultured in the presence of microencapsulated powders of lavender extracts. (Variant 1 blue, variant 2 red, variant 3 green and variant 4 purple) after $24 \mathrm{~h} \mathrm{(a)} \mathrm{and}$ $48 \mathrm{~h}(\mathrm{~b})$. The results were expressed as a relative percentage to the untreated control sample, considered $100 \%$ viable. The values represent mean values $\pm \operatorname{SD}(n=3),{ }^{*} p<0.05$ compared to the control sample.

It can be seen that variants one and two had a similar behavior; after $24 \mathrm{~h}$ of culture, variants 1 and two were cytocompatible in the concentration range $10-500 \mu \mathrm{g} / \mathrm{mL}$, and the values for cell viability varied between 80 and $98 \%$. At higher concentrations, fibroblast viability decreased to $54 \%$, indicating moderate cytotoxicity. After $48 \mathrm{~h}$, variants one and two stimulated cell proliferation in the concentration range of $10-100 \mu \mathrm{g} / \mathrm{mL}$ and $10-50 \mu \mathrm{g} / \mathrm{mL}$, respectively. Values for cell viability were significantly higher than those for control $(p<0.05)$, ranging from 108 to $120 \%$. This behavior can be correlated with the release of biologically active compounds from encapsulated matrices.

Microencapsulated variant three was cytocompatible in the concentration range 10-750 $\mu \mathrm{g} / \mathrm{mL}$ after $24 \mathrm{~h}$ of culture (83-99\% cell viability) and in the range of $10-250 \mu \mathrm{g} / \mathrm{mL}$ after $48 \mathrm{~h}(90-101 \%$ cell viability). At higher concentrations, cell viability decreased to $42 \%$ after $48 \mathrm{~h}$. The encapsulation matrix may not have allowed the release of biologically active compounds or the amount released has not sufficiently stimulated cell viability. 
After $24 \mathrm{~h}$ of cultivation, variant four was cytocompatible throughout the tested concentration range of $10-1000 \mu \mathrm{g} / \mathrm{mL}$, but after $48 \mathrm{~h}$ of culture, the cytocompatibility interval decreased to $10-500 \mu \mathrm{g} / \mathrm{mL}$. Concentrations of $750-1000 \mu \mathrm{g} / \mathrm{mL}$ showed moderate cytotoxicity after $48 \mathrm{~h}$ of cultivation $(50-70 \%$ cell viability). In addition, variant four stimulated cell proliferation at concentrations between 100 and $500 \mu \mathrm{g} / \mathrm{mL}$ even after $24 \mathrm{~h}$ of culture and at concentrations of $100 \mu \mathrm{g} / \mathrm{mL}$ after $48 \mathrm{~h}$ of culture. These results indicate a rapid release of biologically active compounds, which exerted a stimulating effect on cellular metabolism.

Zhang et al. [32] used an in vitro test on six different cells to evaluate the cytotoxicity of the citron extracts, showing that cytotoxicity increased in some cell lines, like hCPCs, hEPCs, and H9C2, after treatment with peptide and liposome based citron nanoparticles. However, the citron-peptide complex caused genotoxicity in the NIH-3T3 and H9C2 cell lines, but not cytotoxicity.

Aprodu et al. [33] also studied the effect of black rice anthocyanins microencapsulated in milk proteins and peptides as possible toxic compounds on L929 fibroblast cell culture, suggesting that treatment with higher concentrations of microencapsulated powders $(750-1000 \mu \mathrm{g} / \mathrm{mL})$ induced a decrease in cell viability, but the values were higher than $80 \%$, indicating non-cytotoxicity.

\subsection{Value Added Food Products}

The powders were added as ingredients in two products, namely ice cream and macaroons. The variants one and two were added in ice cream, whereas variants three and four were added in macaroons in proportions of $1 \%$. The products were tested for antioxidant activity in order to demonstrate the added value. The antioxidant activities of the ice cream samples were $1.22 \pm 0.04 \mathrm{mMol}$ Trolox/g D.W. for $\mathrm{I}_{\mathrm{M}}, 1.54 \pm 0.05 \mathrm{mMol}$ Trolox/g D.W. for $\mathrm{I}_{1}$, and $1.65 \pm 0.02 \mathrm{mMol}$ Trolox/g D.W. for $\mathrm{I}_{2}$. It can be seen that the antioxidant activity was higher in the products with added powders, with approx. $26 \%$ and $35 \%$ in $\mathrm{I}_{1}$ and $\mathrm{I}_{2}$, respectively.

The macaroons showed rather high antioxidant activity, of $9.40 \pm 0.49 \mathrm{mMol}$ Trolox/g D.W. for $\mathrm{M}_{\mathrm{M}}$, $9.73 \pm 0.04 \mathrm{mMol}$ Trolox/g D.W. for $\mathrm{M}_{3}$ and $11.28 \pm 1.08 \mathrm{mMol}$ Trolox/g D.W. for $\mathrm{M}_{4}$, respectively. In this case, the increase in antioxidant activity was with only $3.5 \%$ in case of $\mathrm{M}_{3}$ and with $20 \%$ in case of $\mathrm{M}_{4}$. Some important aspects should be considered in choosing the food matrix to which these functional ingredients are added, and these are the possible interactions between components and the thermal processing, that may lead to the degradation of biologically active compounds. This may explain why in ice cream samples, the added value is higher compared to the macaroons, which underwent a baking step.

\section{Conclusions}

The actual trend in developing natural ingredients with diverse biological functionalities, such as flavoring, antimicrobial and antioxidant activities, thus providing potential health benefits was exploring in our study. Lavender is a rich source of valuable volatiles, carotenoids, chlorophylls, polyphenols, flavonoids with significant biological activities and application on therapy. Two selected extraction methods were comparatively analyzed, based on phytochemical content, namely supercritical fluids and ultrasound assisted extractions. The applied extraction techniques were different in approach, methodology and costs, involving the use of the organic solvents assisted by ultrasound and extraction with supercritical fluids $\left(\mathrm{CO}_{2}\right.$ supercritical). The obtained results evidence both quantitative and qualitative differences among the extracts. The richest extracts, in terms of amount of isolated compounds, were those obtained with supercritical fluids extraction. The extract processed through supercritical fluids had a wider spectrum of volatile compounds and fatty acids, as well as significantly higher contents of chlorophylls, carotenoids and polyphenols when compared with ultrasound-assisted extracts. Although the supercritical method allows effective and quick extraction, operates with moderate temperatures, eliminates clean-up steps, avoids the use of harmful organic solvents, it requires significant investments in equipment and maintenance. 
When extracted, the biological and technological applications of bioactives can be compromised, as they are generally sensitive to oxidation and high temperatures, which lead to marked discoloration during processing and storage. Therefore, complex coarcevation and freeze-drying were applied to obtain stable powders, based on different polymers' combinations. The powders were characterized for total phytochemical and morphological profiles, with a better encapsulating efficiency for proteins, but with a higher content of encapsulated carotenoids for polysaccharides, the latter showing remarkable antimicrobial activity.

Carboxymethyl cellulose and whey proteins led to a double encapsulation of the lipophilic compounds from the lavender extract, although the finest and the most homogeneous powders were obtained when acacia gum and casein were used. The selected variants showed a cytocompatible behavior in certain concentration, whereas some proliferation of cells were highlighted due to the release of the bioactives from microcapsules.

Significant knowledge was provided by the current study from the perspectives of developing ingredients, with targeted multiple functions, such as flavoring, antimicrobial, antioxidant activity that can successfully replace synthetic additives and developing value-added food products.

Currently, our studies continue to evaluate the flavor and fatty acids profile of microencapsulated powders and microencapsulation efficiency of the selected compounds.

Supplementary Materials: The following are available online. Figure S1: GC-MS chromatogram for the identification and quantification of volatile compounds from SCE (a) (S45-black, S40-pink) and UAE (b), Figure S2: GC-MS chromatogram for the identification and quantification of total fatty acids from SCE S40 (a) and S45 (b) fractions and UAE (c).

Author Contributions: Conceptualization, N.S. and P.A.; methodology, N.S., L.M., F.V.D., S.A.S., A.O.; validation, N.S., F.V.D., S.A.S., A.O., I.A.; formal analysis, S.D.R., L.M., M.C.; investigation, S.D.R., E.E., I.A., O.C. and V.B.; resources, G.E.B. and G.R.; writing—original draft preparation, N.S.; writing—review and editing, N.S.; supervision, N.S.; project administration, N.S. and P.A.; funding acquisition, G.E.B. All authors have read and agreed to the published version of the manuscript.

Funding: This work was supported by the project "EXPERT", financed by the Romanian Ministry of Research and Innovation, Contract no. 14PFE/17.10.2018. The work of the Carmen-Alina Bolea was supported by the project ANTREPRENORDOC, in the framework of Human Resources Development Operational Programme 2014-2020, financed from the European Social Fund under the contract number 36355/23.05.2019 HRD OP/380/6/13-SMIS Code: 123847. The Integrated Center for Research, Expertise and Technological Transfer in Food Industry is acknowledged for providing technical support.

Conflicts of Interest: The authors declare no conflict of interest.

\section{References}

1. Downham, A.; Collins, P. Colouring our foods in the last and next millennium. Int. J. Food Sci. Technol. 2000, 35, 5-22. [CrossRef]

2. Özkan, G.; Bilek, S.E. Microencapsulation of natural food colourants. Int. J. Nutr. Food Sci. 2014, 3, $145-156$. [CrossRef]

3. Hosikian, A.; Lim, S.; Halim, R.; Danquah, M.K. Chlorophyll extraction from microalgae: A review on the process engineering aspects. Int. J. Chem. Eng. 2010, 2020, 1-11. [CrossRef]

4. Ramos, S. Cancer chemoprevention and chemotherapy: Dietary polyphenols and signaling pathways. Mol. Nutr. Food Res. 2008, 51, 507-526. [CrossRef] [PubMed]

5. Seeram, N.P.; Bourquin, L.D.; Nair, M.G. Cyclooxygenase inhibitory and antioxidant cyanidin glycosides in cherries and berries. Phytomedicine 2001, 8, 362-369. [CrossRef]

6. Kang, Y.R.; Lee, Y.K.; Kim, Y.J.; Chang, Y.H. Characterization and storage stability of chlorophylls microencapsulated in different combination of gum Arabic and maltodextrin. Food Chem. 2019, 272, 337-346. [CrossRef] [PubMed]

7. Ribeiro, J.S.; Veloso, C.M. Microencapsulation of natural dyes with biopolymers for application in food: A review. Food Hydrocol. 2020, 112, 106374. [CrossRef]

8. Jafari, S.M. Nanoencapsulation of Food Bioactive Ingredients: Principles and Applications. Elsevier Academic Press: London, UK, 2017. 
9. Pereira, F.; Baptista, R.; Ladeiras, D.; Madureira, A.M.; Teixeira, G.; Rosado, C.; Fernandes, A.S.; Ascensão, L.; Oliveira Silva, C.; Pinto Reis, C.; et al. Production and characterization of nanoparticles containing methanol extracts of Portuguese Lavenders. Measurement 2015, 74, 170-177. [CrossRef]

10. Zuzarte, M.; Goncalves, M.J.; Cavaleiro, C.; Dinis, A.M.; Canhoto, J.M.; Salgueiro, L.R. Chemical composition and antifungal activity of the essential oils of Lavandula pedunculata (Miller). Chem. Biodiv. 2009, 6, 1283-1292. [CrossRef] [PubMed]

11. Zuzarte, M.; Goncalves, M.J.; Cruz, M.T.; Cavaleiro, C.; Canhoto, J.M.; Vaz, S.; Pinto, E.; Salgueiro, L.R. Lavandula luisieri essential oil as a source of antifungal drugs. Food Chem. 2012, 135, 1505-1510. [CrossRef]

12. Teixeira, G.; Correia, A.I.; Vasconcelos, T.; Duarte, A.; Oliveira, N.; Madureira, A.M. Lavandula stoechas subsp. luisieri and L. pedunculata: Comparative antibacterial activity. Phytother. Res. 2012, 1, 11-15.

13. Kim, N.S.; Lee, D.D. Comparison of different extraction method for the analysis of fragrance from Lavandula species by gas chromatography-mass spectrometry. J. Chromat. A 2002, 982, 31-47.

14. Da Porto, C.; Decorti, D.; Kikic, I. Flavour compounds of Lavandula angustifolia L. to use in food manufacturing: Comparison of three different extraction methods. Food Chem. 2009, 112, 1072-1078.

15. Radu (Lupoae), D.S.; Râpeanu, G.; Bahrim, G.E.; Stănciuc, N. Investigations on thermal degradationof phytochemicals from lavender extract. Ann. Univ. Dunarea Jos Galati Fascicle VI-Food Technol. 2019, 43, $33-47$.

16. Danh, L.T.; Han, L.N.; Triet, N.D.A.; Zhao, J.; Mammucari, R.; Foster, N. Comparison of chemical composition, antioxidant and antimicrobial activity of lavender (Lavandula angustifolia L.) essential oils extracted by supercritical $\mathrm{CO}_{2}$, hexane and hydrodistillation. Food Bioproc. Technol. 2013, 6, 3481-3489.

17. Dulf, F.V.; Vodnar, D.C.; Socaciu, C. Effects of solid-state fermentation with two filamentous fungi on the total phenolic contents, flavonoids, antioxidant activities and lipid fractions of plum fruit (Prunus domestica L.) by-products. Food Chem. 2016, 209, 27-36.

18. Socaci, S.A.; Socaciu, C.; Tofană, M.; Raţi, I.V.; Pintea, A. In-tube extraction and GC-MS Analysis of Volatile Components from Wild and Cultivated sea buckthorn (Hippophae rhamnoides L. ssp. Carpatica) Berry Varieties and Juice. Phytochem. Anal. 2013, 24, 319-328.

19. The Pherobase: Database of Pheromones and Semiochemicals. Available online: http://www.pherobase.com (accessed on 20 March 2018).

20. Flavornet and Human Odor Space. Available online: http://www.flavornet.org (accessed on 15 March 2018).

21. Guo, G.; Wang, Y.; Chou, S.; Cui, H.; Li, D.; Li, B. In vitro antioxidant capacities of eight different kinds of apples and their effects on lipopolysaccharide-induced oxidative damage in mice. PLoS ONE 2018, 13, e0191762.

22. Cortes-Zavaleta, O.; Lopez-Malo, A.; Hernandes-Mendoza, A.; Garcia, H.S. Antifungal activity of lactobacilli and its relationship with 3-phenyllactic acid production. Int. J. Food Microbiol. 2014, 173, 30-35. [PubMed]

23. Crăciunescu, O.; Gaspar, A.; Trif, M.; Moisei, M.; Oancea, A.; Moldovan, L.; Zarnescu, O. Preparation and characterization of a collagen-liposome-chondroitin sulfate matrix for inflammatory disorders treatment. J. Nanomat. 2014, 2014, 9.

24. Komes, K.; Belščak-Cvitanović, A.; Horžić, D.; Rusak, G.; Likić, S.; Berendika, M. Phenolic composition and antioxidant properties of some traditionally used medicinal plants affected by the extraction time and hydrolysis. Phytochem. Anal. 2010, 22, 172-180. [PubMed]

25. Lesage-Meessen, L.; Bou, M.; Sigoillot, J.C.; Faulds, C.B.; Lomascolo, A. Essential oils and distilled straws of lavender and lavandin: A review of current use and potential application in white biotechnology. Appl. Microbiol. Biotechnol. 2015, 99, 3375-3385. [PubMed]

26. Flores, F.P.; Singh, R.K.; Kong, F. Anthocyanin extraction, microencapsulation and release properties during in vitro digestion. Food Rev. Int. 2016, 32, 46-67.

27. Kirimer, N.; Mokhtarzadeh, S.; Demirci, B.; Goger, F.; Khawar, K.M.; Demirci, F. Phytochemical profiling of volatile components of Lavandula angustifolia Miller propagated under in vitro conditions. Ind. Crops Prod. 2017, 96, 120-125.

28. Kitahara, T.; Koyama, N.; Matsuda, J.; Aoyama, Y.; Hirakata, Y.; Kamihira, S.; Kohno, S.; Nakashima, M.; Sasaki, H. Antimicrobial Activity of Saturated Fatty Acids and Fatty Amines against Methicillin-Resistant Staphylococcus aureus. Biol. Pharm. Bull. 2004, 27, 1321-1326.

29. Czerwińska, E.; Szparaga, A. Antibacterial and antifungal activity of plant extracts. Ann. Set Env. Prot. 2015, 17, 209-229.

30. Bidgoli, R.D.; Ebrahimabadi, A.H.; Heshmati, G.A.; Pessarakli, M. Antioxidant and antimicrobial activity evaluation and essential oil analysis of Artemisia aucheri Boiss. From Iran. Curr. Res. Chem. 2013, 5, 1-10. 
31. Kravchenko, I.A.; Golovenko, N.Y.; Larionov, V.B.; Aleksandrova, A.I.; Ovcharenko, N.V. Effect of lauric acid on transdermal penetration of phenazepam in vivo. Bull. Exp. Biol. Med. 2003, 6, 579-581.

32. Zhang, X.; Yoon, H.J.; Kang, M.G.; Kim, G.J.; Shin, S.Y.; Baek, S.H.; Lee, J.G.; Bai, J.; Lee, S.Y.; Choi, M.J.; et al. Identification and evaluation of cytotoxicity of peptide liposome incorporated citron extracts in an in vitro system. Int. J. Mol. Sci. 2018, 19, 626. [CrossRef]

33. Aprodu, I.; Milea, S.A.; Anghel, R.M.; Enachi, E.; Barbu, V.; Craciunescu, O.; Rapeanu, G.; Bahrim, G.E.; Oancea, A.; Stănciuc, N. New functional ingredients based on microencapsulation of aqueous anthocyanin-rich extracts derived from black rice. Molecules 2019, 24, 3389. [CrossRef]

Sample Availability: Samples of the compounds are not available from the authors.

Publisher's Note: MDPI stays neutral with regard to jurisdictional claims in published maps and institutional affiliations.

(C) 2020 by the authors. Licensee MDPI, Basel, Switzerland. This article is an open access article distributed under the terms and conditions of the Creative Commons Attribution (CC BY) license (http://creativecommons.org/licenses/by/4.0/). 